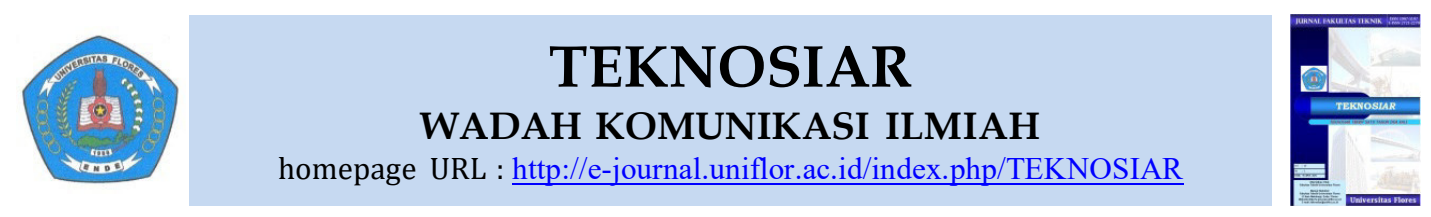

\title{
Analisis Perilaku Struktur Gedung Berkolom Masif Dan Berlubang
}

\author{
Aprilia Romana Tuga ${ }^{1}$, *Yohanes Laka Suku², Marselinus Y. Nisanson ${ }^{3}$ \\ ${ }^{1}$ Alumni Program Studi Teknik Sipil, Fakultas Teknik, Universitas Flores, Ende \\ ${ }^{2,3}$ Program Studi Teknik Sipil, Fakultas Teknik, Universitas Flores, Ende \\ *) Correspondence, e-mail: mayokonco@yahoo.co.id
}

Received: 30-03-2020 Revised: 10-04-2020 Accepted: 18-04-2020

\begin{abstract}
ABSTRAC
Columns are important structural elements in building structures that function to support and transmit axial loads and moments to the foundation structure. Perforated columns are often used as conduits for plumbing, mechanical and electrical pipes for aesthetic purposes. Research on the behavior of building structures with massive and perforated columns aims to determine the behavior of perforated column structures with holes $3 \%, 4 \%, 5 \%$ and $6 \%$ of the cross-sectional area of the columns. The observed behavior is the vibration time of the structure, the basic shear force, deviation, and overturning moment. The results of the analysis show that the structural model with the perforated column has a vibration time of less than the required maximum structure vibration. Due to the heavy holes, the structure of the perforated column is lighter than the structure with massive columns, thereby reducing the basic shear forces, deviations and rolling moments in structures with massive columns.
\end{abstract}

Keywords: massive column, hollow column, building structure

\begin{abstract}
ABSTRAK
Kolom merupakan elemen struktur penting dalam struktur bangunan gedung yang berfungsi menopang dan meneruskan beban aksial dan momen ke struktur pondasi. Kolom berlubang sering digunakan sebagai conduit tempat perpipaan plumbing, mekanikal dan elektrikal untuk tujuan estetika. Penelitian perilaku struktur gedung berkolom massif dan berlubang bertujuan mengetahui perilaku struktur kolom berlubang dengan luasan lubang 3\%, 4\%, 5\% dan 6\% dari luasan penampang kolom. Perilaku yang diamati berupa waktu getar struktur, gaya geser dasar, simpangan, dan momen guling. Hasil analisis diperoleh bahwa model struktur dengan kolom berlubang tersebut mempunyai waktu getar struktur lebih kecil dari getar struktur maksimum yang disyaratkan. Akibat adanya lubang berat struktur kolom berlubang menjadi lebih ringan dibandingkan dengan struktur dengan kolom massif sehingga mereduksi gaya geser dasar, simpangan dan momen guling pada struktur dengan kolom massif.
\end{abstract}

Kata kunci: kolom massif, kolom berlubang, struktur gedung

\section{PENDAHULUAN}

Struktur gedung bagian atas umumnya tersusun dari elemen kolom, balok dan plat yang berfungsi menahan berbagai gaya yang terjadi dan menyalurkannya ke struktur pondasi. Struktur kolom yang berfungsi menahan beban aksial dan meneruskannya ke struktur fondasi menjadi elemen struktur yang sangat penting, karena kegagalan struktur kolom dapat menyebabkan runtuhnya bangunan. Penggunaan kolom berlubang sebagai conduit untuk kepentingan mekanikal, elektrikal dan

TEKNOSIAR Volume 14, No.01, April 20 p-ISSN 1907-5197 (versi cetak) e-ISSN 2721-2270 (versi online) 
plumbing pada konstruksi bangunan gedung sering digunakan. Bangunan gedung yang menggunakan kolom berlubang akan mempunyai berat total bangunan lebih ringan dari gedung yang berkolom masif, sehingga biaya bangunannya relative lebih murah.

Dari segi kekuatan struktur, penggunaan kolom berlubang dapat mempengaruhi perilaku struktur secara keseluruhan. Penelitian tentang perilaku struktur kolom sehubungan dengan kepentingan estetika dan efisiensi berupa kolom berlubang telah banyak dilakukan, hasil penelitian diperoleh bahwa adanya lobang pada kolom dan ukuran berlubang mempengaruhi kinerja struktur secara keseluruhan jika dibandingkan dengan kolom masif (Kim, 2012; Suku \& Je, 2020; Zacoeb, 2006). Oleh sebab itu penggunaan luas berlubang pada kolom perlu dibatasi, yang mana pada Standar Nasional Indonesia (SNI) 2847-2013 membatisi ukurang luas berlubang yang dapat digunakan yang tertanam pada kolom tidak boleh lebih dari 4\% luas penampang kolom. Penelitian pengaruh luas berlubang terhadap kekuatan kolom yang dilakukan oleh Sabariman, Purwono, \& Priyosulistyo (2004) diperoleh pada luas berlubang 4\% kekuatan momen kolom masih menunjukan kekuatan yang sama dengan kolom tidak berlubang tetapi jika luas berlubang lebih besar dari 4\% menyebabkan terjadinya penurunan daktilitas kolom (Sabariman, Purwono, \& Priyosulistyo, 2004), demikian pula hasil penelitian yang dilakukan oleh Marzon, Islam \& Elhusna (2018) diperoleh bahwa pada luas berlubang 7\% menyebabkan penurunan kekuatan sebesar 16,97\% (Marzon, Islam, \& Elhusna, 2018).

Penelitian ini bertujuan mengetahui pengaruh kolom berlubang terhadap perilaku struktur gedung yakni antara struktur gedung kolom berlubang dan struktur gedung berkolom massif. Dalam penelitian ini akan dipelajari pengaruh rasio luasan lubang pada kolom berlubang terhadap kinerja bangunan berupa besarnya gaya geser, simpangan, dasar dan momen guling, dengan membandingkannya pada struktur gedung kolom masif (tidak berlubang).

\section{Tinjauan Pustaka}

Kolom adalah elemen yang berfunsi menahan beban tekan arah vertikal dari sistim rangka struktur bangunan. Karena kolom merupakan komponen tekan, maka keruntuhan pada kolom dapat menyebabkan keruntuhan dari seluruh strukturnya. Oleh karena itu dalam merencanakan kolom perlu dilakukan secara baik dengan memberikan kekuatan yang lebih tinggi daripada pada balok dan elemen struktur horizontal lainnya. Berbagai penelitian yang telah dilakukan tentang perilaku struktur dengan kolom berlubang diperoleh bahwa luasan berlubang pada kolom berpengaruh terhadap kekuatan kolom dan kekuatan struktur secara keseluruhan (Kim, 2012; Suku \& Je, 2020; Zacoeb, 2006).

Keruntuhan kolom struktural harus dihindari, sehingga dalam merencanakan struktur bangunan, struktur kolom perlu direncanakan lebih kuat daripada struktur pada balok dan struktur elemen horisontal bangunan. Secara umum kolom dapat diklasifikasikan berdasarkan bentuk dan susunan tulangannya, posisi beban pada penampangnya, dan panjang kolom dalam hubungannya dengan dimensi lateralnya yakni: Kolom segiempat atau bujursangkar dengan tulangan memanjang dan sengkang, . Kolom bundar dengan tulangan memanjang dan tulangan lateral berupa sengkang atau spiral, dan Kolom komposit yang terdiri atas beton dan profil baja struktural di dalamnya. Berdasrkan posisi beban terhadap penampang melintang, kolom dapat diklasifikasikan sebagai Kolom dengan beban sentris dan Kolom dengan beban eksentris. Pada beberapa kasus untuk kepentingan estetika kolom sering dilubanggi dan diletakkan pipa/conduit untuk media elektrikal dan plumbing. Gambar 1 memperlihatkan kolom yang diberi lubang pada inti kolomnya.
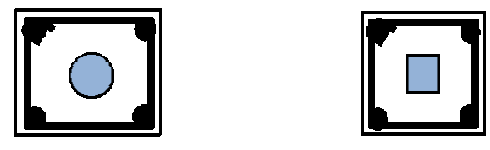

TEKNOSIAR Volume 14, No.01, April 20

p-ISSN 1907-5197 (versi cetak) e-ISSN 2721-2270 (versi online) 
Gambar 1. Kolom diberi lubang pada intinya

Kekuatan kolom dalam memikul beban didasarkan pada kombinasi beban axial (Pu) dan Momen $\mathrm{Mu}$ secara bersamaan, oleh sebab itu dalam perencanaan kolom didasarkan pada kekuatan dan kekakuan penampang lintangnya terhadap aksi beban aksial dan momen lentur. Pada kasus tertentu kolom hanya mengalami beban axial (beban sentris)dan jika beban tersebut bergeser (beban eksentris) dari sumbu kolomnya, maka akan timbul momen, sehingga kolom harus dapat memikul kombinasi beban aksial dan momen. Akibat kombinasi beban tersebut, maka keruntuhan penampang kolom dapat dikelompokan dalam 4 jenis kondisi keruntuhan, yakni: kondisi keruntuhan tekan, kondisi keruntuhan balance, kondisi keruntuhan tarik, dan kondisi lentur murni.

Pada kondisi kolom yang berlubang, maka kekuatan kolom untuk menahan beban axial dan momen akan menurun disebabkan karena berkurangnya luas penampang kolom (Kim, 2012; Suku \& Je, 2020; Zacoeb, 2006). Berdasarkan gambar 2. dapat dilihat bahwa kapasitas kolomdalam memikul momen akan menurun manakala tinggi blok tekan beton (a) mencapai lubang kolom, hal ini disebabkan berkurangnya luas penampang akibat lubang di dalam kolom tersebut. Tinggi blok tekan kolom akan mengalami penyesuaian menjadi a' dan gaya tekan beton juga mengalami penurunan menjadi Cc'.

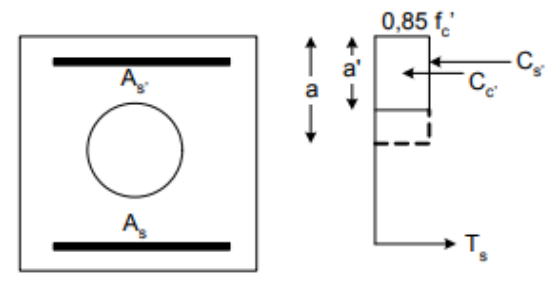

Gambar 2. Diagram tegangan kolom berlubang

Kekuatan penampang kolom berlubang yang terdiri dari kuat menahan beban axial dan momen dapat diperoleh dengan persamaan:

Dimana:

$$
\begin{aligned}
& \mathrm{Pn}=0,65\left[-\mathrm{Ts}+\mathrm{Cc} \mathrm{c}^{\prime}+\mathrm{Cs}{ }^{\prime}\right] \ldots \ldots \ldots \ldots \ldots \ldots \ldots \ldots \ldots \ldots \ldots \ldots \ldots \\
& \mathrm{Mn}=0,65\left[\mathrm{Ts} \cdot \mathrm{Zs}+\mathrm{Cc} \cdot \mathrm{Zc}+\mathrm{Cs} \mathrm{s}^{\prime} . \mathrm{Zs} \mathrm{s}^{\prime}\right] \ldots \ldots \ldots \ldots \ldots \ldots
\end{aligned}
$$

$$
\begin{aligned}
& \text { Ts }=\text { As.fs } \\
& \text { Cc' }=0,85 . f c^{\prime} . a^{\prime} . b \\
& \text { Cs }=\text { As'.fs' } \\
& \text { Zs, Zc', Zs' masing-masing adalah lengan momen gaya dalam kolom beton berlubang. }
\end{aligned}
$$

\section{Data Pemodelan Struktur Gedung}

Struktur bangunan gedung yang dimodelkan dalam penelitian ini adalah struktur gedung beton bertulang 3 lantai yang berfungsi sebagai perkantoran, terletak di Kabupaten Ende dan dengan jenis tanah sedang (SD), model struktur gedung diperlihatkan pada gambar 3. Untuk mengetahui pengaruh kolom berlubang pada struktur gedung tersebut, maka dibuat 5 model yakni: 1) Model struktur kolom massif (M1), 2) Model struktur kolom berlubang 3\% luas penampang, 3) Model struktur kolom berlubang 4\% luas penampang, 4) Model struktur kolom berlubang 5\% luas penampang dan 5) Model struktur kolom berlubang 6\% luas penampang. 


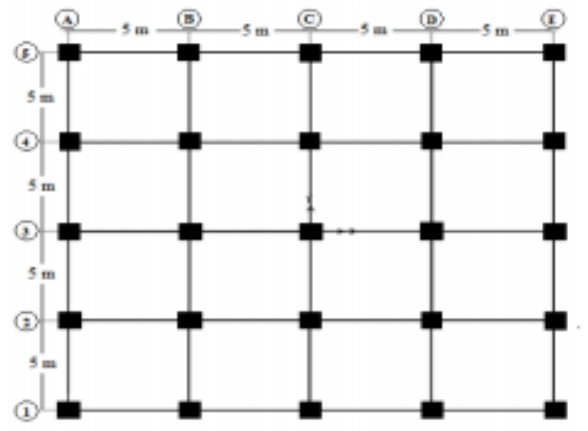

a. Denah

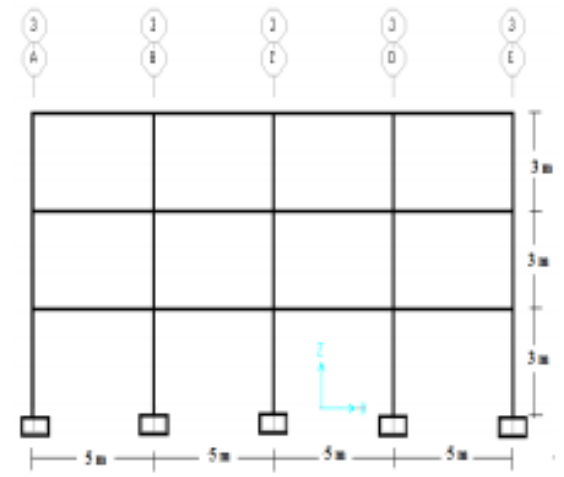

b. Portal

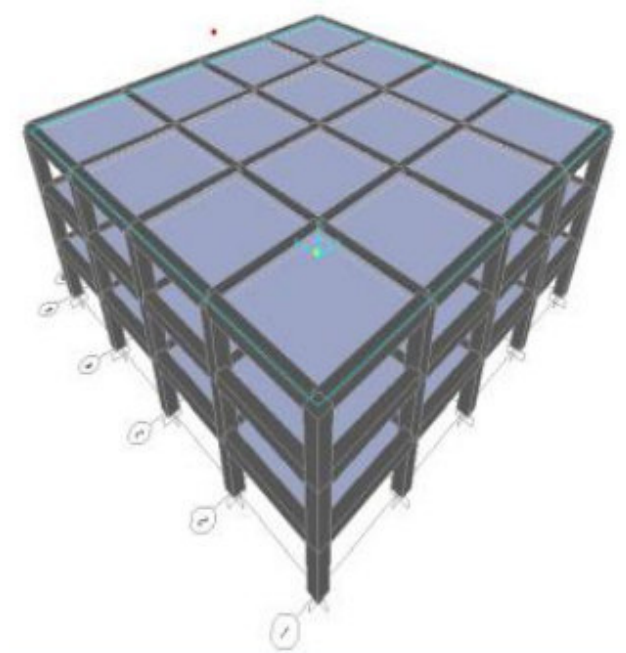

c. Model 3 dimensi

Gambar 3. Pemodelan struktur gedung

Data dimensi bangunan dan elemen struktur balok, kolom pelat yang digunakan disajikan pada tabel 1. sebagai berikut:

Tabel 1. Data Bangunan

\begin{tabular}{lll}
\hline No & \multicolumn{1}{c}{ Uraian } & \multicolumn{1}{c}{ Dimensi } \\
\hline 1 & Ukuran bangunan & $20 \mathrm{~m} \mathrm{\times} \mathrm{20} \mathrm{m}$ \\
\hline 2 & Tinggi bangunan & $9 \mathrm{~m}$ \\
\hline 3 & Ukuran balok & $500 \mathrm{~mm} \times 700 \mathrm{~mm}$ \\
\hline 4 & Ukuran kolom & $600 \mathrm{~mm} \times 600 \mathrm{~mm}$ \\
\hline & a. $\quad$ Lubang 3\% & $104 \mathrm{~mm} \times 104 \mathrm{~mm}$ \\
\hline & b. $\quad$ Lubang 4\% & $120 \mathrm{~mm} \times 120 \mathrm{~mm}$ \\
\hline & c. $\quad$ Lubang 5\% & $134 \mathrm{~mm} \times 134 \mathrm{~mm}$ \\
\hline 5 & d. Lubang 6\% & $147 \mathrm{~mm} \times 147 \mathrm{~mm}$ \\
\hline 6 & Ukuran Pelat & Tebal $150 \mathrm{~mm}$ \\
\hline
\end{tabular}

TEKNOSIAR Volume 14, No.01, April 20

p-ISSN 1907-5197 (versi cetak) e-ISSN 2721-2270 (versi online) 
Aprilia Romana Tuga, Yohanes Laka Suku, Marselinus Y. Nisanson

Analisis Perilaku Struktur Gedung Berkolom Masif Dan Berlubang

\begin{tabular}{lll}
\hline 7 & Mutu baja (fy) & $420 \mathrm{MPa}$ \\
\hline 8 & Berat volume beton & $24 \mathrm{kN} / \mathrm{m}^{3}$ \\
\hline 9 & Tumpuan & Jepit \\
\hline
\end{tabular}

\section{Pembebanan}

Pembebanan struktur terdiri dari beban mati, hidup dan gempa dimana besarnya beban tersebut diambil berdasarkan standar pembebanan SNI 03-1727-2013, tentang Beban Minimum Untuk Perancangan Gedung dan Struktur Lain (BSN, 2013). Untuk beban gempa ditentukan berdasarkan SNI 03-1726-2012, Tata Cara Perencanaan Ketahanan Gempa Untuk Struktur Bangunan Gedung dan Non Gedung (BSN, 2012). Parameter gempa untuk lokasi di Ende dengan jenis tanah sedang diperoleh percepatan gempa pada periode pendek $(\mathrm{Ss})=1,006 \mathrm{~g}$ dan pada periode 1 detik $(\mathrm{S} 1)=$ $0,369 \mathrm{~g}$, serta Parameter respon spektra disain, untuk periode pendek $\left(\mathrm{SD}_{\mathrm{S}}\right)=0,736 \mathrm{~g}$ dan periode 1 detik $\left(\mathrm{SD}_{1}\right)=0,409 \mathrm{~g}$. Besarnya respon spectrum disaian untuk jenis tanah sedang lokasi di Ende disajikan pada Gambar 4.

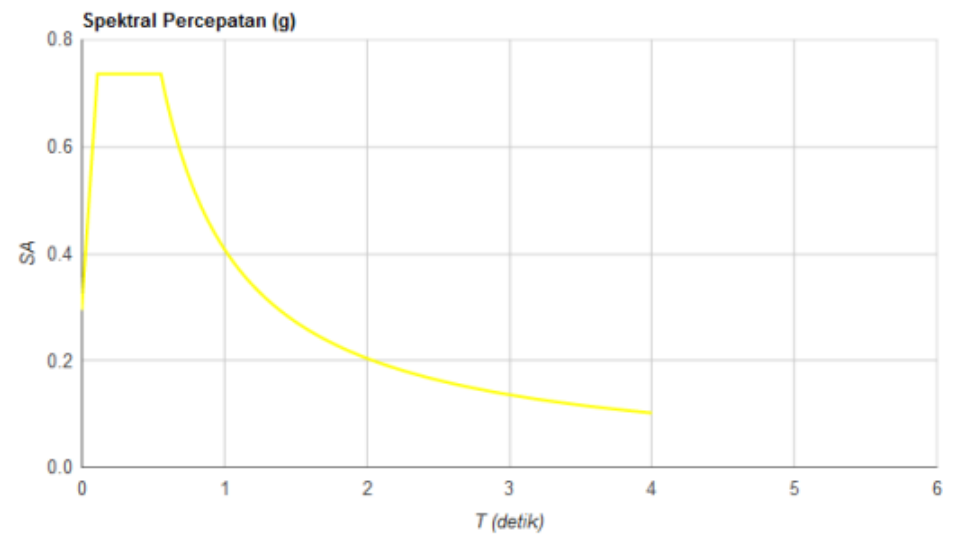

Gambar 4. Grafik respon spektrum lokasi Ende jenis tanah sedang

Dari data parameter gempa dan gambar respon spectrum, diketahui bahwa nilai $S_{D S}>0,50$ dan $S_{D 1}$ $>0,20$ dengan demikian Ende berada pada wilayah dengan kategori resiko gempa (KDG) D atau resiko gempa tinggi (BSN, 2012), hasil penelitian Suku dan Angkasa (2014) tentang analisis probabilitas resiko gempa (probabilistic seismic hazard analysis) kota Ende berdasarkan fungsi atenuasi joyner-boore dan youngs, diperoleh bahwa Ende mempunyai resiko gempa yang tinggi (Suku \& Angkasa, 2014).

\section{Tahapan Analisis}

Tahapan analisis dimulai dengan membuat model dan mendefenisikan material, elemen struktur dan beban. Mula-mula dilakukan analisis tehadap struktur gedung bertulangan massif untuk memastikan bahwa semua elemen struktur dan struktur secara keseluruhan berada pada kondisi aman. Setelah itu dilakukan pemodelan dan analisis struktur dengan kolom berlubang. Tahapan analisis dapat dilihat pada gambar 5 . 


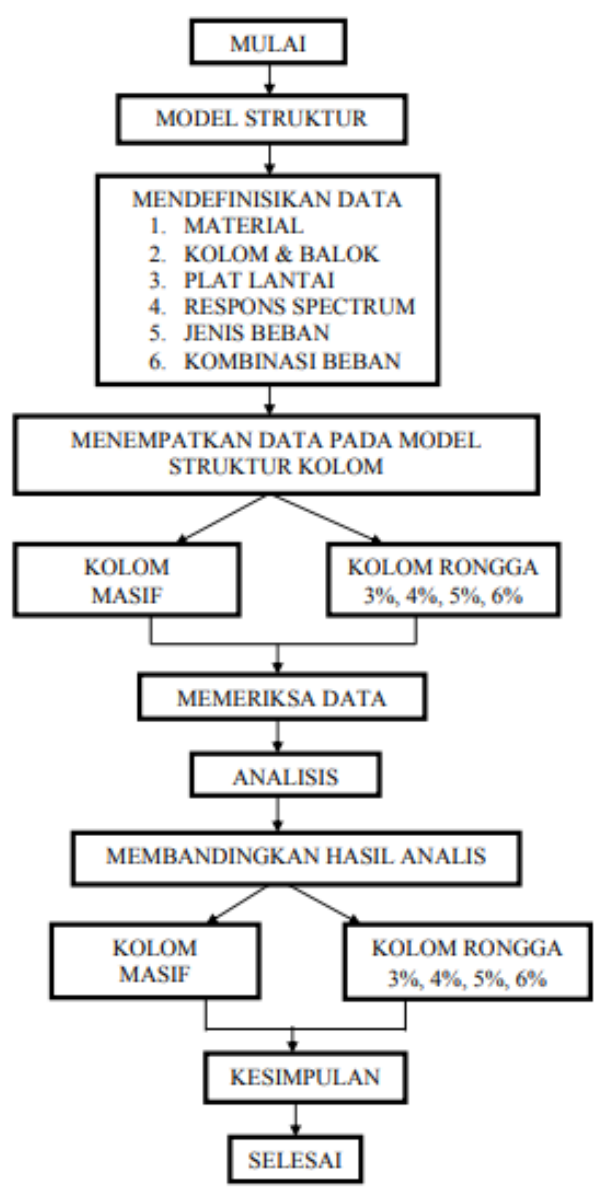

Gambar 5. Grafik tahapan analisis

\section{Hasil dan Pembahasan \\ Periode getar struktur}

Periode getar stuktur yang terjadi yang diperoleh dari hasil analisis $\left(\mathrm{T}_{\mathrm{c}}\right)$, harus lebih kecil dari batasan peroide struktur yang diijinkan $\left(T_{\max }\right)$ yang ditetapkan oleh peraturan (BSN, 2012). Dimana, $T_{\max }=C_{u} \cdot T_{a}=1,4 . T_{a}$, perbandingan nilai $T_{c}$ dan $T_{\max }$ disajikan pada tabel 2.

Tabel 2. Periode getar struktur

\begin{tabular}{ccccc}
\hline No & Model Struktur & $\mathbf{T}_{\mathbf{C}}($ detik) & $\mathbf{T}_{\max }$ (detik) & Keterangan \\
1 & Kolom masif & 0,26234 & 0,4704 & Memenuhi \\
2 & Lubang 3\% & 0,25997 & 0,4704 & Memenuhi \\
3 & Lubang 4\% & 0,26004 & 0,4704 & Memenuhi \\
4 & Lubang 5\% & 0,26015 & 0,4704 & Memenuhi \\
5 & Lubang 6\% & 0,26026 & 0,4704 & Memenuhi \\
\hline
\end{tabular}

TEKNOSIAR Volume 14, No.01, April 20 
Dari tabel 2. terlihat bahwa sumua model struktur mempunyai periode getar bangunan alami lebih kecil dari batasan maksimum periode getar yang diijinkan, dengan demikian seluruh model struktur mempunyai kekakuan memenuhi persyaratan batas periode getar alami.

\section{Gaya geser dasar}

Gaya geser dasar yang terjadi diakibatkan oleh gaya lateral/gempa yang terjadi pada bangunan. Perbandingan gaya geser dasar yang terjadi pada model struktur dapat dilihat pada Gambar 6 .

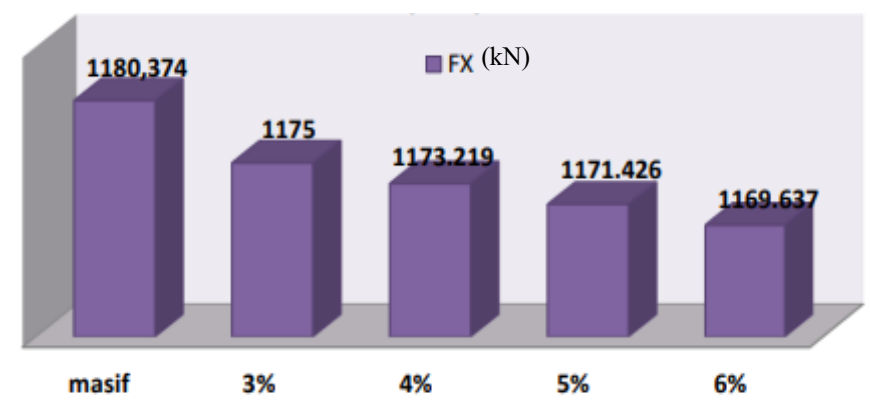

Gambar 6. Gaya geser dasar arah $\mathrm{x}=\mathrm{y}$

Dari gambar 6. terlihat bahwa dengan adanya lubang pada kolom dapat mereduksi gaya geser dasar yang terjadi, dimana pada ukuran luas lubang 6\% dari luas penampang, gaya geser dasar yang terjadi berkurang sebesar 1\%. Hal ini terjadi karena akibat adanya lubang pada kolom, mengurangi berat struktur secara keseluruhan.

\section{Simpangan struktur}

Simpangan struktur maksimum yang terjadi pada model struktur ditampilkan pada gambar 7 . Dari gambar tersebut terlihat bahwa dengan adanya lubang pada kolom terjadi penurunan simpangan maksimum yang tidak signifikan, dimana pada luas lubang $6 \%$ penurunan simpangan hanya sebesar $0,004 \mathrm{~mm}$. Adanya penurunan ini dikarenakan struktur dengan kolom berlubang relatif menjadi lebih ringan dari struktur berkolom massif sehingga beban gempa dan gaya geser dasar yang terjadi lebih kecil (Abhay, 2014).

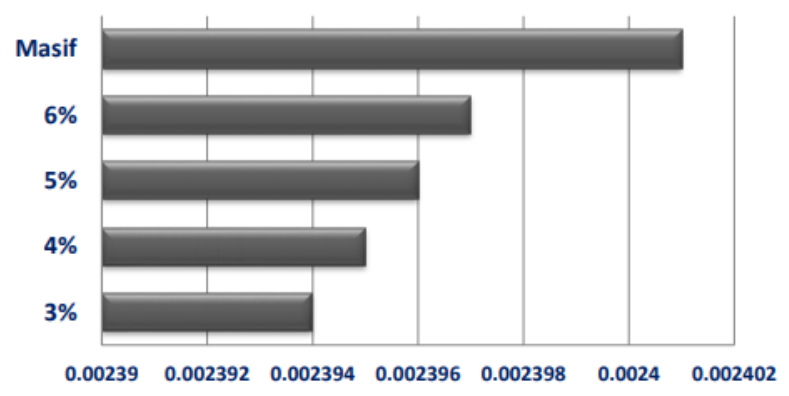

Gambar 7. Simpangan maksimum struktur

TEKNOSIAR Volume 14, No.01, April 20 


\section{Momen guling (Overturning Moments)}

Momen guling terjadi akibat adanya beban lateral/gempa yang terjadi pada struktur. Momen guling maksimum yang terjadi pada model struktur untuk arah $\mathrm{x}$ dan y disajikan pada gambar 8 . Dari gambar 8. terlihat bahwa dengan adanya lubang pada kolom dapat mereduksi momen guling struktur.

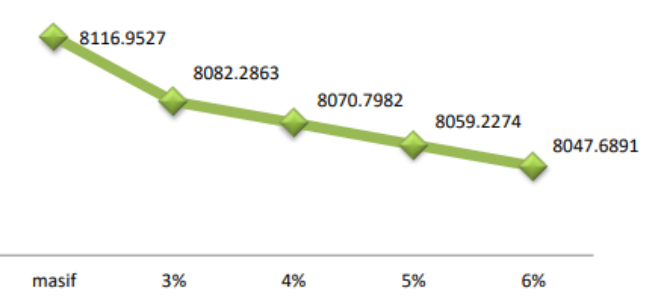

a. $\operatorname{arah} \mathrm{x}$
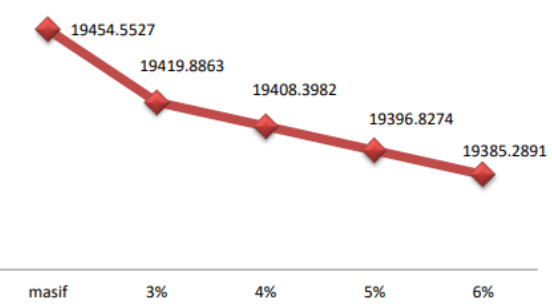

$\operatorname{arah} \mathrm{y}$

Gambar 8. Momen guling yang terjadi pada model struktur

\section{Kesimpulan}

Dari hasil analisis dan pembahasan terhadap 5 model struktur gedung yang diteliti dapat disimpulakan beberapa hal sebagai berikut:

1. Dari 5 model struktur gedung yang dianalisis yakni struktur dengan kolom massif, berongga $3 \%, 4 \%, 5 \%$ dan $6 \%$, mempunyai waktu getar struktur lebih kecil dari batas maksimum yang diijinkan.

2. Struktur dengan kolom berlubang 3\%, $4 \%, 5 \%$ dan $6 \%$, mempunyai gaya geser dasar, simpangan dan momen guling maksimum lebih kecil dari struktur berkolom massif, hal ini dikarenakan struktur dengan kolom berlubang relative lebih ringan dari struktur dengan kolom massif.

3. Penggunaan kolom berlubang pada struktur gedung beton bertulang dapat mereduksi beban gempa dan dapat menghemat biaya konstruksi, karena berat struktur secara keseluruhan menjadi berkurang dan juga akan mengurangi luasan pondasi bangunan.

\section{Daftar Pustaka}

Abhay. (2014). Comparison Of Seismic Performance Of Solid And Hollow Reinforced Concrete Members In RCC Framed Building Using ETABS Software. International Journal Of Advances In Engineering Sciences, 4(4), 43-47.

BSN. (2012). SNI 1726: 2012, Tatacara Perencanaan Ketahanan Gempa Untuk Struktur Bangunan Gedung Dan Non Gedung Jakarta: Badan Standardisasi Nasional.

BSN. (2013). Persyaratan Beton Struktural Untuk Bangunan Gedung (SNI 2847: 2013) Jakarta: Badan Standardisasi Indonensia (BSN). 
Kim, T.-H. (2012). Inelastic Behavior Of Hollow Reinforced Concrete Bridge Columns. 15th WCEE.

Marzon, Islam, M., \& Elhusna. (2018). Analisis Penampang Kolom Beton Bertulang Persegi Panjang Berlubang. Inersia, 10(2), 1-12.

Sabariman, B., Purwono, R., \& Priyosulistyo. (2004). Efek Pengekangan Kolom Berlubang Beton Mutu Normal Terhadap Daktilitas Kurvatur. Civil Engineering Dimension, 6(1), 7-14.

Suku, Y. L., \& Angkasa, R. S. (2014). Analisis Probabilitas Resiko Gempa ( Probabilistic Seismic Hazard Analysis) Kota Ende Berdasarkan Fungsi Atenuasi Joyner-Boore Dan YOUNGS. Majalah Ilmiah Indikator, 17(2), 1-18.

Suku, Y. L., \& Je, K. (2020). Modeling And Analysis Of The Effect Of Holes In Reinforced Concrete Column Structures. Journal Of The Civil Engineering Forum, 6(1). Doi: $10.22146 /$ Jcef. 48722

Zacoeb, A. (2006). Ductility Of Hollow RC Short Columns In Compression Region. Dinamika Teknik Sipil, 6(1), 1-6. 